\title{
Fibular strut allograft influences reduction and outcomes after locking plate fixation of comminuted proximal humeral fractures in elderly patients: a retrospective study
}

Xueliang Cui ${ }^{1,2,3}$, Hui Chen ${ }^{1,2,3^{*}}$ (D), Binbin Ma ${ }^{1,2,3}$, Wenbin Fan ${ }^{1,2,3}$ and He Li ${ }^{1,2,3}$

\begin{abstract}
Background: Proximal humeral fractures (PHFs) are the third most commonly occurring fractures in elderly patients. Most of these fractures can be treated with conservative methods, but the optimal surgical treatment strategy for unstable fractures in elderly patients remains controversial. This study aimed to compare the radiological and clinical outcomes between locking compression plate (LCP) fixation and LCP fixation with fibular allograft implantation for the treatment of comminuted PHFs.
\end{abstract}

Methods: We retrospectively reviewed 60 patients (mean age, 72.75 years) with closed 3- or 4-part fractures, and a minimum of 2 years of follow-up. Fracture reduction was quantitatively determined by humeral head height $(\mathrm{HHH})$ and neck-shaft angle (NSA). The clinical outcome was evaluated by Constant-Murley score (CMS) and American Shoulder and Elbow Surgeons (ASES) score.

Result: The average radiological changes were higher in the LCP group than in the locking plate with fibular allograft group (HHH of $4.16 \mathrm{~mm}$ vs $1.18 \mathrm{~mm}[p<0.001]$ and NSA of $9.94^{\circ}$ versus $3.12^{\circ}[p<0.001]$ ). The final average outcome scores were lower in the LCP group than in the FA group (CMS of 73.00 vs $78.96[p=0.024]$ and ASES score of 72.80 vs $78.64[p=0.022])$. The FA group showed better forward elevation $(p=0.010)$ and abduction $(p=$ 0.002); however, no significant differences were observed for shoulder external rotation or internal rotation. The number of complications was higher in the LCP group (28.57\%) than in the FA group (1.2\%) $(p<0.001)$.

Conclusion: For comminuted PHFs in elderly patients, LCP fixation combined with a fibular allograft is reasonable option to ensure satisfactory radiological and clinical outcomes.

Trial registration: ZDYJLY(2018)New-9. Name of registry: IEC for clinical Research of Zhongda Hospital, Affiliated to Southeast University. Date of registration: 2018-05-17.

Keywords: Proximal humeral fracture, Fibular allograft, Locking plate, Elderly patients

\section{Background}

Proximal humeral fractures (PHFs) are common in elderly patients with osteoporosis [1]. The prevalence of PHFs is rapidly increasing because of an increasing elderly population worldwide [2]. Most of these fractures

\footnotetext{
* Correspondence: chenhui@seu.edu.cn

${ }^{1}$ Department of Orthopaedics, Zhongda Hospital, Southeast University, 87 Ding Jia Qiao, Nanjing, Jiangsu 210009, People's Republic of China

${ }^{2}$ Trauma Center, Zhongda Hospital, Southeast University, 87 Ding Jia Qiao,

Nanjing, Jiangsu 210009, People's Republic of China

Full list of author information is available at the end of the article
}

are non-displaced and can be treated with conservative methods. However, the optimal surgical treatment of unstable, displaced two-, three- and four-part fractures in geriatric patients remains controversial [3].

Locking plate fixation is currently the most widely used method for the management of unstable PHFs [4]. However, achieving stable fixation and maintaining intraoperative reduction in elderly patients with low bone mineral density is still difficult [5]. Complications including screw perforation and varus malalignment are often reported [6, 7]. Establishment of the medial

(c) The Author(s). 2019 Open Access This article is distributed under the terms of the Creative Commons Attribution 4.0 International License (http://creativecommons.org/licenses/by/4.0/), which permits unrestricted use, distribution, and reproduction in any medium, provided you give appropriate credit to the original author(s) and the source, provide a link to the Creative Commons license, and indicate if changes were made. The Creative Commons Public Domain Dedication waiver (http://creativecommons.org/publicdomain/zero/1.0/) applies to the data made available in this article, unless otherwise stated. 
column support is well known to achieve successful clinical outcome and reduce the complication rate $[8,9]$. Various techniques have been advocated to reduce and enhance the medical column, such as cement augmentation, inferomedial screws, and allograft [10]. Many biomechanical studies have reported that the combined use of a locking compression plate (LCP) and fibular allograft could increase the initial stiffness and sustain a higher ultimate failure load [11, 12]; however, only a few comparative clinical studies have been performed to date.

Thus, this study aimed to compare the radiological and clinical outcome between LCP (LCP group) and LCP with fibular allograft (FA group) in the treatment of comminuted PHFs. We hypothesized that elderly patients treated with the LCP and fibular strut allograft would have better outcomes and lower complication rate than those treated with the LCP alone.

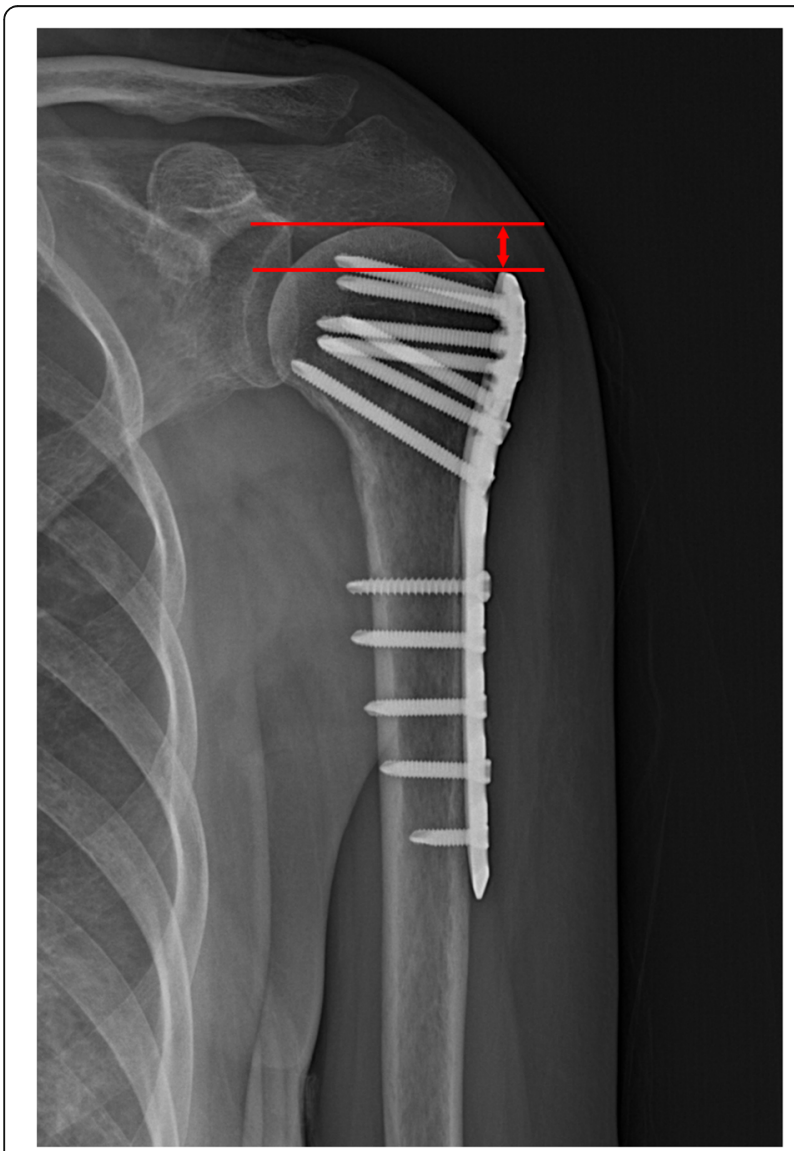

Fig. 1 Calculation of the humeral head height. The two lines drawn running perpendicular to the shaft of the plate; one was placed at the top edge of the plate, and the other was placed at the superior edge of the humeral head. The distance between these two lines was measured and designated as the head height

\section{Methods}

This study was approved by institutional review boards, and written consent was obtained from all patients. This retrospective study included 60 geriatric patients who underwent an open reduction and internal fixation for comminuted PHFs between January 2014 and May 2017. The inclusion criteria were aged 60 years or older, a minimum of 2 years of follow-up, and a diagnosis of displaced three- and four-part PHFs. Patients with pathological fractures, open fractures, fractures that involved articular split of the humeral head, and associated nerve injuries were excluded.

Postoperative radiographs were obtained on the second day, 1 month, 3 months, 6 months, 1 year, and 2 years after the surgery. Radiological evaluation was performed by measuring the humeral head height [13] $(\mathrm{HHH})$ and neck shaft angle (NSA) on true anteroposterior (AP) radiographs (Fig. 1). The NSA was measured

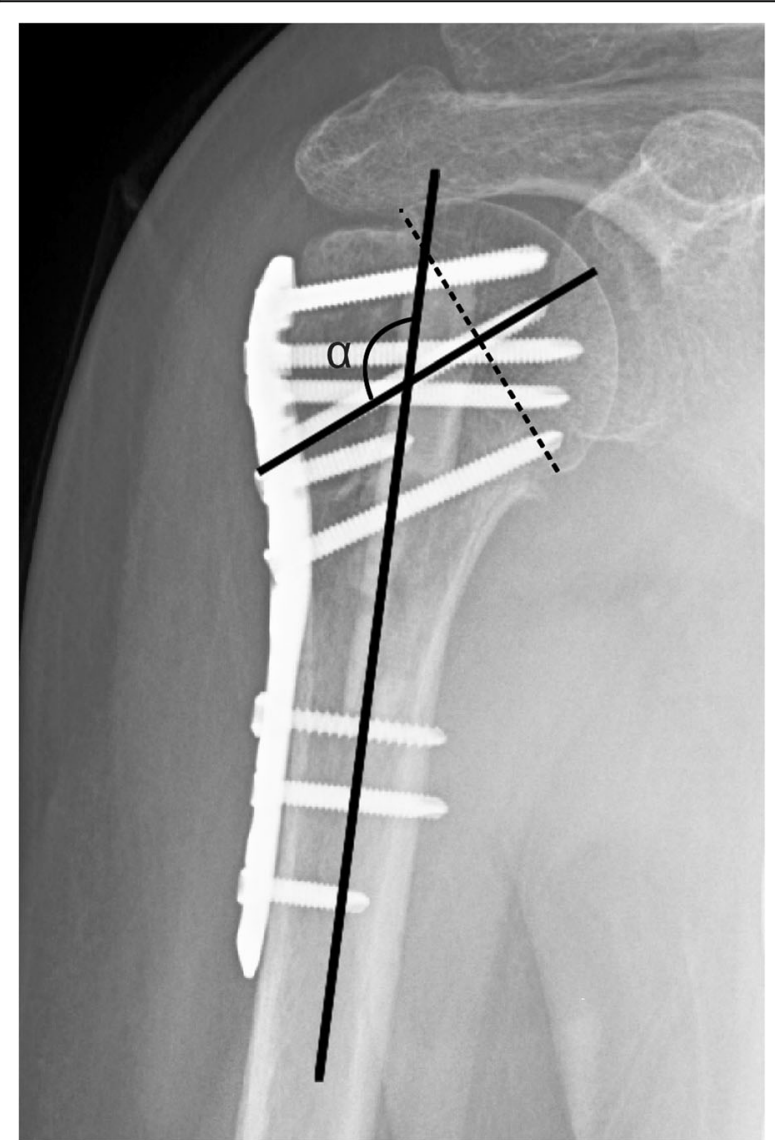

Fig. 2 The head-shaft alignment (angle a) was determined as follows: a first line (dashed line) was drawn from the superior border to the inferior border of the articular surface and a second line was drawn perpendicular to the first line through the center of the humeral head. A third line bisected the humeral shaft, and the angle between the second and third line was defined as the head-shaft angle a 
on AP radiographs with the shoulder in neutral rotation [14]. A line was drawn from the superior to the inferior border of the articular surface. Then, a perpendicular line was drawn through the center of the humeral head. The angle between the perpendicular line and the line bisecting the humeral shaft was defined as the NSA (Fig. 2). A difference in the $\mathrm{HHH}>3 \mathrm{~mm}$ or the NSA > $5^{\circ}$ on the AP radiograph that was taken 2 days after the operation and that obtained at the 2 years follow-up was defined as loss of fixation [15].

Clinical outcomes were evaluated by the American Shoulder and Elbow Society (ASES) [16] score and the Constant-Murley score (CMS) [17]. Shoulder range of motion including forward elevation, external rotation, abduction, and internal rotation was digitally recorded at the first year of follow-up and subsequent yearly evaluation. Complications such as infection, screw perforation, and humeral head necrosis were recorded during follow-up.

\section{Surgical technique}

All patients were positioned in the beach chair position with the injured arms hanging over the edge of the radiolucent operating table. The deltopectoral approach was performed to gain access to the proximal humerus. The humeral head and the fragments were retracted and reduced by placing no. 2 nonabsorbable sutures (Ethicon, Somerville, USA) through the rotator cuff. In the LCP group, anatomical reduction of the fragments was maintained by temporary Kirschner wires and checked by fluoroscopy. Thereafter, a proximal humeral LCP (Synthes, Oberdorf, Switzerland) was placed on the lateral cortex and fixed with cortical and locking screws. The plate was placed $5 \mathrm{~mm}$ inferior to the upper end of the greater tuberosity and $1 \mathrm{~cm}$ posterior to the bicipital groove [18].

In the FA group, the fibular allograft was used to indirectly reduce the fracture. A $1.5-\mathrm{mm}$ guidewire was placed
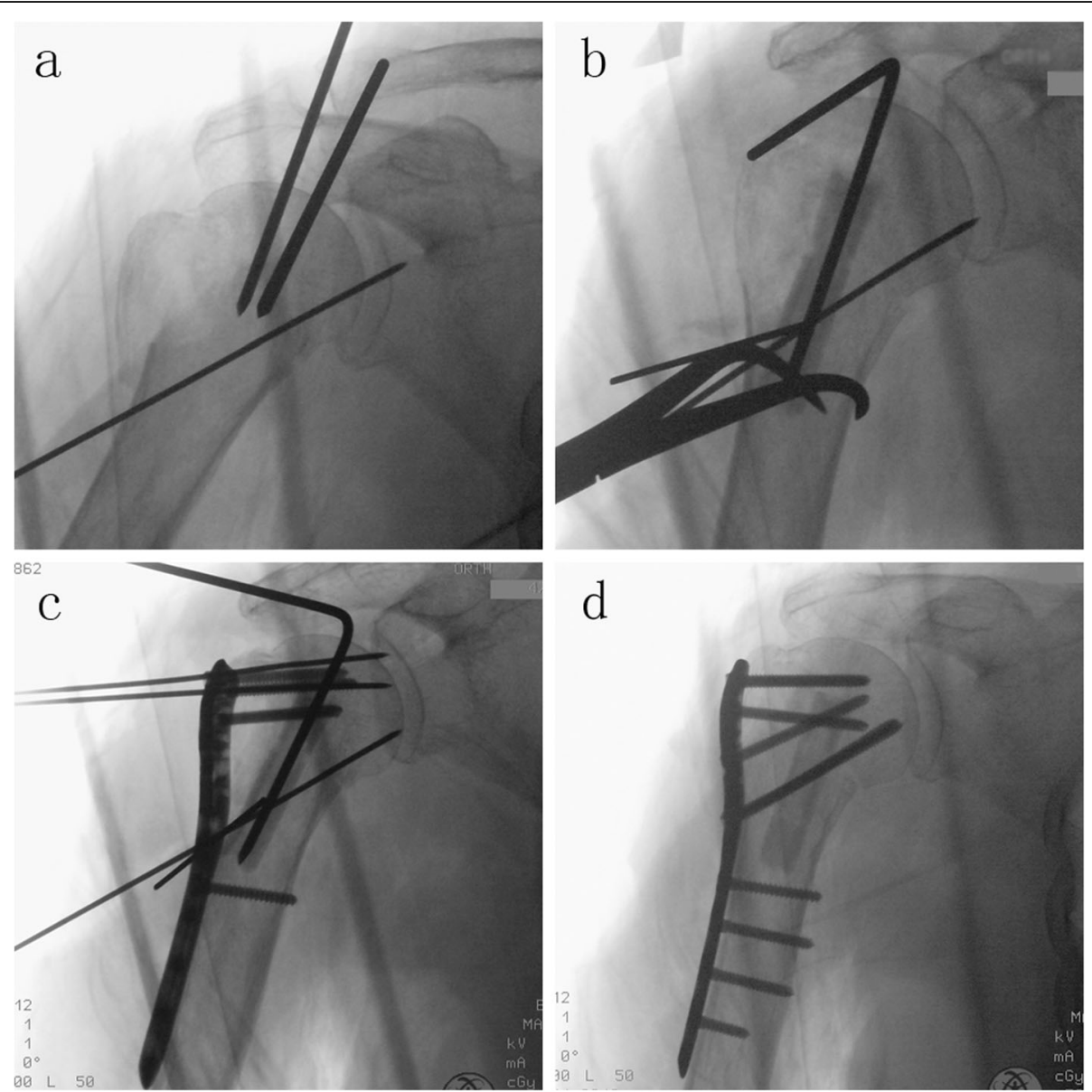

Fig. 3 The reduction and fixation process with a fibular strut allograft. a A $1.5 \mathrm{~mm}$ guidewire was placed $1 \mathrm{~cm}$ posterior to the intertubercular groove and $1 \mathrm{~cm}$ medial to the transition between the head and the greater tuberosity. $\mathbf{b}$ The fibular allograft was inserted into the cavity, through the fracture site, through the guidewire. And then, it was pushed upwards to support the humeral head in a proper height. c After confirming the fracture reduction, a LCP was used to fix the fragments. Locking screws were placed through the graft into the humeral head and shaft. d Post-operative radiograph showing good anatomical reduction 
$1 \mathrm{~cm}$ posterior to the intertubercular groove and $1 \mathrm{~cm}$ medial to the transition between the head and the greater tuberosity. A fibular strut was inserted into the cavity, through the fracture site, and through the guidewire. By this procedure, the proximal fibular allograft was located at the center of the head, and the distal end was positioned in the humeral shaft. The proper height and position of he humeral head could be achieved by pushing the allograft upward instead of medial (Fig. 3). Further, greater tuberosity fragments were reduced and temporarily fixed. A LCP was used to complete the fixation after the fracture reduction was confirmed under C-arm. Locking screws were used to pass through the allograft to lock its position (Fig. 4). Two infer-medial calcar screws were also inserted to provide additional support.

A sling was provided to immobilize the arm during the first 4 weeks after surgery in both groups. Continuous pendulum and passive range-of-motion exercises were started 2 days postoperatively. Active assisted range-ofmotion exercises were followed at 4 weeks. The patients could start to do daily activities according to the tolerance of the patients and the fracture union status.

\section{Statistical analysis}

Statistical analysis was performed using SPSS software version 18.0 (SPSS Inc., Chicago, IL, USA). Continuous data and scores for the LCP and FA groups were evaluated with an independent $t$ test. Differences in proportions were compared with a chi-square test and Fisher's exact test. The threshold for significance was set at $p<0.05$.

\section{Results}

A total of 60 patients (26 men and 34 women) were included in this study. The LCP group comprised 35 patients, of which 25 patients had three-part fractures and 10 had four-part fractures. The FA group consisted of 25 patients, of which 17 patients had three-part fractures and 8 had four-part fractures. In the LCP group, 18 patients experienced medial comminution, and the mean follow-up period was 32.23 (range, 25-40) months. In the FA group, 13 patients experienced medial comminution, and the mean follow-up period was 31.56 (range, 24-40) months (Table 1).

In the LCP group, the average change in $\mathrm{HHH}$ was $4.16 \mathrm{~mm}$ (range, $0-13 \mathrm{~mm}$ ), a change in $\mathrm{HHH}>3 \mathrm{~mm}$ appeared in 18 patients. The average change in NSA was $9.94^{\circ}$ (range, $0-30^{\circ}$ ), a change in NSA $>5^{\circ}$ appeared in 20 patients. In the FA group, the average change in $\mathrm{HHH}$ was $1.18 \mathrm{~mm}$ (range, $0-13 \mathrm{~mm}$ ), a change in $\mathrm{HHH}$ $>3 \mathrm{~mm}$ appeared in 3 patients. The average change in NSA was $3.12^{\circ}$ (range, $0-8^{\circ}$ ), a change in NSA $>5^{\circ}$ appeared in 4 patients (Fig. 5).

The CMS, ASES scores, and shoulder range of motion for all patients are presented in Table 2. Compared with the LCP group, the FA group had significantly better mean CMS (78.96 versus $73.00 ; p=0.024$ ) and ASES scores $(78.64$ versus $72.80 ; p=0.022)$. At 2 years, the active forward elevation, abduction, external rotation, and internal rotation of the shoulder were $128.49 \pm 22.81^{\circ}$, $122.37 \pm 22.31^{\circ}, 55.09 \pm 8.63^{\circ}$, and L1, respectively, in the LCP group compared with $144.04 \pm 21.37^{\circ}, 140.64 \pm$ $20.34^{\circ}, 58.96 \pm 8.49^{\circ}$, and T12 in the FA group (Fig. 6).
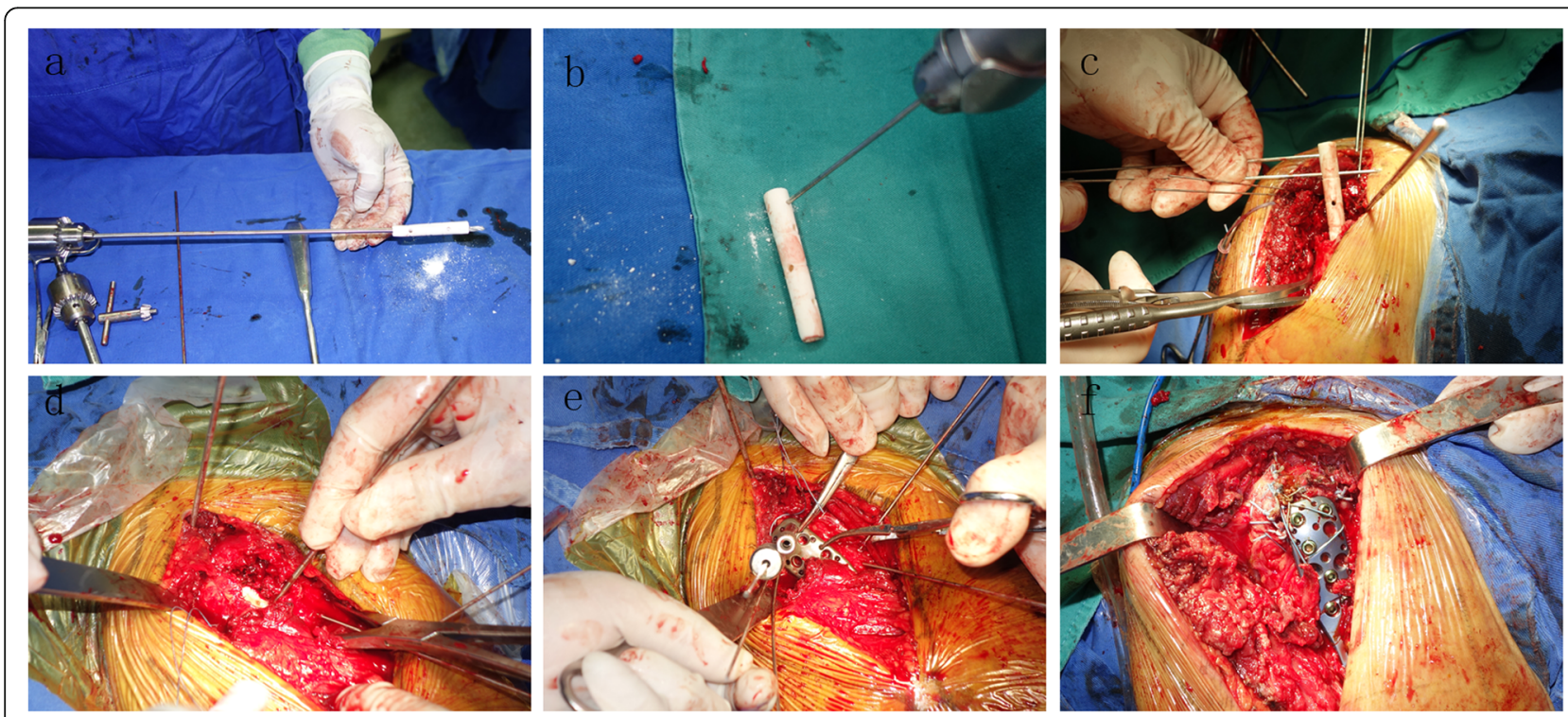

Fig. 4 surgical procedure $(\mathbf{a}, \mathbf{b})$ Holes were drilled on the fibular allograft to make the fibula easily maneuvered into position. c The fibular allograft was inserted into the cavity through the bone defect. $\mathbf{d}$ Without the exposure of medial calcar, the medial column could be indirectly reduced to pushing the fibular allograft upwards. e A proximal locking plate was used to fix the greater tuberosity to the humeral head. $\mathbf{f}$ Multiple non-absorbable sutures were passed to compress comminuted fragments to the bony defect of the proximal humerus 
Table 1 Demographic characteristics data for patients included in this study

\begin{tabular}{llll}
\hline Characteristic & LCP Group $(n=35)$ & FA Group $(n=25)$ & $P$-value \\
\hline Average age (year) & 72.46 & 73.16 & 0.566 \\
Sex distribution (male: female) & $11: 24$ & $7: 18$ & 0.775 \\
Dominant arm involvement & $17: 18$ & $13: 12$ & 0.793 \\
The mean time from injury to surgery (day) & 4.69 & 4.48 & 0.237 \\
Te mechanism of injury (F: TA) & $27: 8$ & $20: 5$ & $17: 8$ \\
Classifcation of Neer (3 part: 4 part) & $25: 10$ & $13: 12$ & 0.791 \\
Medial comminution & $18: 17$ & 31.56 & 0.775 \\
The mean follow-up period (months) & 32.23 & & 0.965 \\
\hline
\end{tabular}

$L C P$ locking compression plate, $F A$ fibular allograft

Significant difference in active forward elevation $(p=$ $0.010)$ and abduction $(p=0.002)$ of the shoulder was found between the two groups. No significant difference in the mean external rotation values $(p=0.090)$ and internal rotation values $(p=0.438)$ was noted between the two groups. There were 12 complications in 10 of 35 patients $(28.57 \%)$ in the LCP group, including varus malunion in 5 , screw penetration in 5 , and avascular necrosis in 2. In the FA group, one patient presented screw penetration, and two patients developed avascular necrosis of the humeral head.

\section{Discussion}

This study compared the LCP group and the FA group involving three- and four-part PHFs in patients aged 60 years or older and evaluated the influence of fibular
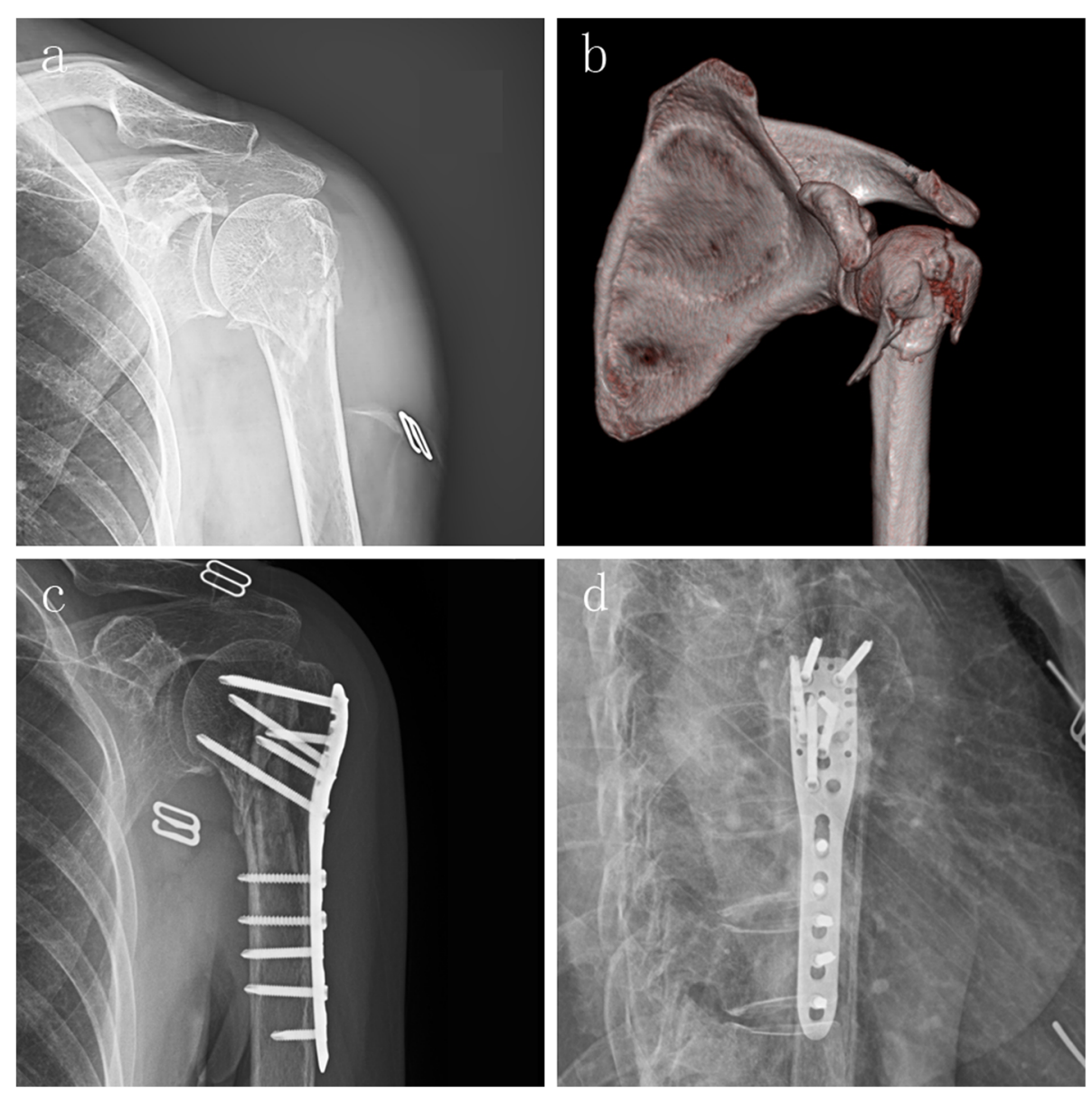

Fig. 5 A case of a 3-part fracture with severe metaphyseal comminution. a Radiograph of a displaced 3-part humeral fracture in the left shoulder of a 73-year-old woman. b CT scan, 3-D reconstruction view. (c, d) Radiograph 1 year after surgery 
Table 2 Radiographic Evaluation, Outcome Scores and Rangeof-Motion Data for the Study Population

\begin{tabular}{llll}
\hline Variable & LCP Group $(n=35)$ & FA Group $(n=25)$ & $P$-value \\
\hline $\mathrm{HHH}(\mathrm{mm})^{\mathrm{a}}$ & $4.16 \pm 4.2$ & $1.18 \pm 1.08$ & $<0.001$ \\
$\mathrm{NSA}^{\mathrm{a}}$ & $9.94 \pm 9.92^{\circ}$ & $3.12 \pm 3.13^{\circ}$ & $<0.001$ \\
$\mathrm{CMS}^{\mathrm{a}}$ & $73.00 \pm 9.94$ & $78.96 \pm 9.71$ & 0.024 \\
ASES $^{\mathrm{a}}$ & $72.80 \pm 9.73$ & $78.64 \pm 9.18$ & 0.022 \\
Forward elevation $^{\mathrm{a}}$ & $128.49 \pm 22.81^{\circ}$ & $144.04 \pm 21.37^{\circ}$ & 0.010 \\
Abduction $^{\mathrm{a}}$ & $122.37 \pm 22.31^{\circ}$ & $140.64 \pm 20.34^{\circ}$ & 0.002 \\
Internal rotation $^{\mathrm{b}}$ & L1 $^{\circ}$ buttock-T5) & T12 level (L5-T5) & 0.438 \\
External rotation $^{\mathrm{a}}$ & $55.09 \pm 8.63^{\circ}$ & $58.96 \pm 8.49^{\circ}$ & 0.090 \\
\hline
\end{tabular}

LCP locking compression plate, $F A$ fibular allograft, $\mathrm{HHH}$ humeral head height, NSA neck shaft angle, ASES American Shoulder and Elbow Society score, CMS Constant-Murley score

${ }^{\mathrm{a}}$ The values are given as the mean and standard deviation. ${ }^{\mathrm{b}}$ The values are given as the mean with the range in parentheses. ${ }^{\circ}$ degree

allograft on the radiological and clinical outcomes. PHFs treated by LCP and fibular allograft showed significantly better clinical outcomes, and a lower complication rate. The FA group also showed superior radiological results regardless of the fracture type.

The treatment of unstable and displaced PHFs in elderly patients remains a challenge [19]. Anatomical reduction is difficult to maintain because of the poor quality of the humeral head, and many surgeons believe that LCP fixation is a promising treatment for this problem [20]. Compared to the standard nonlocking plate, the screw fixation angle can be oriented in different directions when an LCP is used, and the locking screw provides stable fixation maintenance [21]. However, many studies have reported variable outcomes, with high rates of complications, including screw penetration, varus collapse, and avascular necrosis of the humeral head, especially in older patients with osteoporosis or medial column comminution [22, 23]. Ockert et al. [24] reported 10-year outcomes after operative treatment with LCP for unstable and displaced PHFs, and the majority of the patients obtained good or excellent outcomes. However, poor outcomes and complications were found in older and female patients. In recent years, many efforts have made to overcome these problems. Clinical and biomechanical studies have paid increased attention to allograft augmentation to increase the stability of locking plate fixation in PHFs. Gardner et al. [25] were the first to introduce this technique using fibular strut allograft to indirectly reduce the fracture and maintain the fixation; in their study, all of the seven fractures achieved complete union without loss of fixation.

Mathison et al. [12] first made a biomechanical comparison between locking plate alone and locking plate with fibular allograft. They created a $10-\mathrm{mm}$ wedgeshaped osteotomy at the lever of the surgical neck to simulate the comminution of the medial column. Loaddisplacement curve was used to test failure load and stiffness of the constructs. Their study demonstrated that the bone peg increased the failure load and the initial stiffness of the constructs. Relative to locking plate
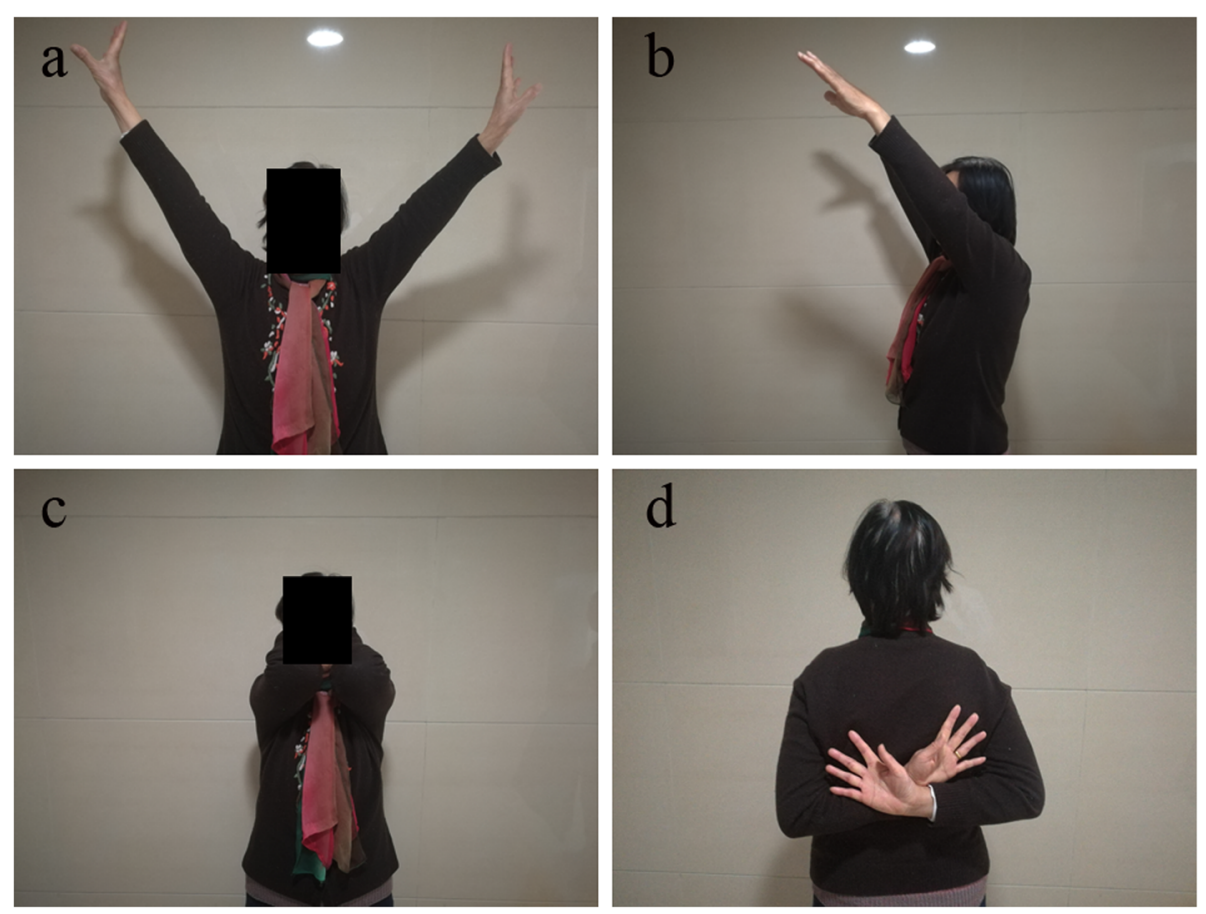

Fig. 6 Clinical function 2 years after surgery. a Active abduction. b Active forward elevation. c Active external rotation. $d$. Active internal rotation 
fixation alone, failure load was increased by 1.72 times and the initial stiffness was increased by 3.84 times. Chow et al. [11] performed a similar study to evaluate the effect of a fibular allograft. No augmented construct collapsed before 25,000 cycles, while most of the specimens in the non-augmented locking compression group collapsed at mean 6604 cycles. Neviaser et al. [26] retrospectively reviewed 38 patients treated by locking plate with endosteal strut augment, and they reported high clinical outcome scores and lower complication rate. Recently, Panchal et al. [27] assessed the effect of intramedullary fibular allograft on the clinical and radiological outcomes in unstable PHFs with medial column disruption. According to the clinical rating scale, 26 patients had excellent or good outcomes, six patients showed fair outcomes, and only four patients experienced poor outcomes. With regard to the restoration of the humeral NSA, the result was good in 31, fair in three, and poor in two cases. When calculating the $\mathrm{HHH}$, the average loss of reduction was measured as $1.6 \mathrm{~mm}$. Only two cases experienced varus collapse of the humeral head, and osteonecrosis was noted in two patients. Cha et al. [15] compared the radiological outcomes of using only LCP and using LCP with fibular allograft in the treatment of comminuted PHFs. The change in the NSA and $\mathrm{HHH}$ in the LCP group was markedly higher.

In our opinion, the fibular allograft was a reasonable option to maintain the anatomical reduction in the treatment of comminuted PHFs in the elderly patients. The fibular allograft could be used as tool to indirectly reduce the fracture. Gardner et al. [25] first introduced the use of screw to push the fibular allograft medially so that the graft could indirectly reduce the fractured medial cortex. Subsequently, many authors preferred to push the graft upward instead of medial because it could support the humeral head in a proper height $[15,28]$. However, in some cases, the intramedullary cavity in elderly patients accompanied osteoporosis was relatively large, the graft could not be easily manipulated. So we placed a guide pin at the apex of the humeral head. Then, the fibular allograft was pushed upward in the intramedullary cavity through the guide pin as in retrograded nailing. Especially in cases with medial cortex disruption, using fibular allograft as a pillar to support the humeral head from intramedullary cavity was more helpful in maintaining reduction. The added stability provided by the fibular allograft allowed for an early rehabilitation program and reduced the complication rate. In our study, the FA group showed significant lower rates of varus malunion and screw penetration. The fibular allograft also had disadvantages, such as risk of infection, disease transmission, and high cost. The fibular allograft contains cortical bone, so it might be fractured during insertion of the screws.
This study has several limitations. First, it was a retrospective study, and the number of patients was relatively small. Further study with a greater number of patients is needed. Second, the follow-up duration was rather short, as the difference in NSA and HHH might change with longer monitoring. Third, the Neer classification is the most widely used grading system for PHFs, but some studies have shown that the Neer classification only have fair to good reliability.

\section{Conclusion}

Elderly patients treated with an LCP and fibular allograft achieved better radiological outcomes, clinical outcomes, and a lower rate of complications compared with those who treatment with an LCP alone for the treatment of a three- or four-part PHFs. Using the fibular allograft is a reasonable option to help the reduction, provide additional support to the humeral head, improve outcomes, and minimize complications.

\section{Abbreviations \\ AP: Anteroposterior; ASES: American shoulder and elbow society; CMS: Constant-murley score; FA group: Locking plate with fibular allograft; $\mathrm{HHH}$ : Humeral head height; LCP: Locking compression plate; NHA: Neck-shaft angle; PHF: Proximal humeral fractures}

\section{Acknowledgments \\ We would like to thank Editage (www.editage.com) for English language editing.}

Authors' contributions

BBM and WBF participated in the recruitment, data collection, and analysis. $\mathrm{XLC}$ wrote the manuscript. $\mathrm{HC}$ and $\mathrm{HL}$ performed the surgery as main operators. XLC contributed to the study design and conception. All authors read and approved the final manuscript.

Funding

Not applicable.

\section{Availability of data and materials}

The datasets used and analysed during the current study available from the corresponding author on reasonable request.

\section{Ethics approval and consent to participate}

The Institutional Review Board of Zhongda Hospital affiliated to Southeast University reviewed and approved this study. Each author certifies that all investigations were conducted in conformity with ethical principles. Written consent was obtained from all individual participants included in the study.

Consent for publication

The authors have received written consent from participants to publish individual patient data.

\section{Competing interests}

On behalf of all authors, the corresponding author states that there is no conflict of interest.

\section{Author details}

'Department of Orthopaedics, Zhongda Hospital, Southeast University, 87 Ding Jia Qiao, Nanjing, Jiangsu 210009, People's Republic of China. ${ }^{2}$ Trauma Center, Zhongda Hospital, Southeast University, 87 Ding Jia Qiao, Nanjing, Jiangsu 210009, People's Republic of China. ${ }^{3}$ Orthopaedic Trauma Institute (OTI), Southeast University, Nanjing, Jiangsu 210009, People's Republic of China. 
Received: 21 June 2019 Accepted: 22 October 2019

Published online: 03 November 2019

\section{References}

1. Baron JA, Karagas M, Barrett J, Kniffin W, Malenka D, Mayor M, Keller RB. Basic epidemiology of fractures of the upper and lower limb among Americans over 65 years of age. Epidemiology. 1996;7:612-8.

2. Palvanen M, Kannus P, Niemi S, Parkkari J. Update in the epidemiology of proximal humeral fractures. Clin Orthop Relat Res. 2006;442:87-92.

3. Neer CS 2nd. Displaced proximal humeral fractures. Part I. Classification and evaluation. Clin Orthop Relat Res. 2006:442:77-82.

4. Walsh S, Reindl R, Harvey E, Berry G, Beckman L, Steffen T. Biomechanical comparison of a unique locking plate versus a standard plate for internal fixation of proximal humerus fractures in a cadaveric model. Clin Biomech (Bristol, Avon). 2006;21(10):1027-31.

5. Namdari S, Voleti PB, Mehta S. Evaluation of the osteoporotic proximal humeral fracture and strategies for structural augmentation during surgical treatment. J Shoulder Elb Surg. 2012;21(12):1787-95.

6. Gupta AK, Harris JD, Erickson BJ, Abrams GD, Bruce B, McCormick F, Nicholson GP, Romeo AA. Surgical management of complex proximal humerus fractures-a systematic review of 92 studies including 4500 patients. J Orthop Trauma. 2015;29:54-9.

7. Sproul RC, lyengar JJ, Devcic Z, Feeley BT. A systematic review of locking plate fixation of proximal humerus fractures. Injury. 2011;42:408-13.

8. Krappinger D, Bizzotto N, Riedmann S, Kammerlander C, Hengg C, Kralinger FS. Predicting failure after surgical fixation of proximal humerus fractures. Injury. 2011;42:1283-8.

9. Lee CW, Shin SJ. Prognostic factors for unstable proximal humeral fractures treated with locking-plate fixation. J Shoulder Elb Surg. 2009;18:83-8.

10. Kim DS, Lee DH, Chun YM, Shin SJ. Which additional augmented fixation procedure decreases surgical failure after proximal humeral fracture with medial comminution: fibular allograft or inferomedial screws? J Shoulder Elb Surg. 2018;27(10):S1058274618302295.

11. Chow RM, Begum F, Beaupre LA, Carey JP, Adeeb S, Bouliane MJ. Proximal humeral fracture fixation: locking plate construct \pm intramedullary fibular allograft. J Shoulder Elb Surg. 2011;21(7):894-901.

12. Mathison C, Chaudhary R, Beaupre L, Reynolds M, Adeeb S, Bouliane M. Biomechanical analysis of proximal humeral fixation using locking plate fixation with an intramedullary fibular allograft. Clin Biomech (Bristol Avon). 2010;25:642-6.

13. Gardner MJ, Weil Y, Barker JU, Kelly BT, Helfet DL, Lorich DG. The importance of medial support in locked plating of proximal humerus fractures. J Orthop Trauma. 2007;21(3):185-91.

14. Agudelo J, Schürmann M, Stahel P, Helwig P, Morgan SJ, Zechel W, Bahrs C, Parekh A, Ziran B, Williams A, Smith W. Analysis of efficacy and failure in proximal humerus fractures treated with locking plates. J Orthop Trauma. 2007;21(10):676-81.

15. Cha H, Park KB, Oh S, Jeong J. Treatment of comminuted proximal humeral fractures using locking plate with strut allograft. J Shoulder Elb Surg. 2017; 26(5):781-5.

16. Cuff DJ, Pupello D. Hemiarthroplasty vs. reverse shoulder Arthroplasty for the treatment of comminuted proximal humeral fractures in elderly patients. J Bone Joint Surg Am. 2013;95(22):2050-5.

17. Constant CR, Gerber C, Emery RJ, Søjbjerg JO, Gohlke F, Boileau P. A review of the Constant score: modifications and guidelines for its use. J Shoulder Elb Surg. 2008;17(2):0-361.

18. Schnetzke M. Bockmeyer J, Porschke F, studier-Fischer S, Grützner, PaulAlfred, Guehring T. quality of reduction influences outcome after lockedplate fixation of proximal humeral type-C fractures. J Bone Joint Surg Am. 2016:98(21):1777-85.

19. Schliemann B, Siemoneit J, Theisen C, Kösters C, Weimann A, Raschke MJ. Complex fractures of the proximal humerus in the elderly-outcome and complications after locking plate fixation. Musculoskelet Surg. 2012;96(Suppl 1):S3-11.

20. Ricchetti ET, Warrender WJ, Abboud JA. Use of locking plates in the treatment of proximal humerus fractures. J Shoulder Elb Surg. 2010;19:66-75.

21. Gardner MJ, Evans JM, Dunbar RP. Failure of fracture plate fixation. J Am Acad Orthop Surg. 2009:17:647-57.

22. Gardner MJ, Weil Y, Barker JU, Kelly BT, Helfet DL, Lorich DG. The importance of medial support in locked plating of proximal humerus fractures. J Orthop Trauma. 2007;21:185-91.
23. Jiang R, Luo CF, Zeng BF, Mei GH. Minimally invasive plating for complex humeral shaft fractures. Arch Orthop Trauma Surg. 2007;127:531-5.

24. Ockert B. Siebenbürger Georg, Kettler M, Braunstein V, Mutschler W. longterm functional outcomes (median 10 years) after locked plating for displaced fractures of the proximal humerus. J Shoulder Elb Surg. 2014; 23(8):1223-31.

25. Gardner MJ, Boraiah S, Helfet DL, Lorich DG. Indirect medial reduction and strut support of proximal humerus fractures using an endosteal implant. J Orthop Trauma. 2008;22:195-200.

26. Bae JH, Oh JK, Chon CS, Oh CW, Hwang JH, Yoon YC. The biomechanical performance of locking plate fixation with intramedullary fibular strut graft augmentation in the treatment of unstable fractures of the proximal humerus. J Bone Joint Surg (Br). 2011;98(7):937-41.

27. Panchal K, Jeong JJ, Park SE, Kim WY. Clinical and radiological outcomes of unstable proximal humeral fractures treated with a locking plate and fibular strut allograft. Int Orthop. 2016;40(3):569-77.

28. Lee SH, Han SS, Yoo BM, Kim JW. Outcomes of locking plate fixation with fibular allograft augmentation for proximal humeral fractures in osteoporotic patient. Bone Joint J. 2019;101-B(3):260-5.

\section{Publisher's Note}

Springer Nature remains neutral with regard to jurisdictional claims in published maps and institutional affiliations.
Ready to submit your research? Choose BMC and benefit from:

- fast, convenient online submission

- thorough peer review by experienced researchers in your field

- rapid publication on acceptance

- support for research data, including large and complex data types

- gold Open Access which fosters wider collaboration and increased citations

- maximum visibility for your research: over $100 \mathrm{M}$ website views per year

At BMC, research is always in progress.

Learn more biomedcentral.com/submissions 